Original Article

\title{
An Experiment for Assimilating Different Type of Data Observations in Forecasting Heavy Rainfall over Central Highlands Region Due to the Impact of Hurricane Damrey
}

\author{
Le Lan Phuong ${ }^{1}$, Pham Quang Nam², Tran Quang Duc ${ }^{2, *}$, Phan Van Tan ${ }^{2}$ \\ ${ }^{I}$ National Central University, 300 Zhongda Road, Taoyuan, Taiwan \\ ${ }^{2}$ VNU University of Science, 334 Nguyen Trai, Hanoi, Vietnam
}

Received 30 Octorber 2019

Revised 25 November 2019; Accepted 15 December 2019

\begin{abstract}
This study investigates and assesses the impact of assimilating data types (observed data surface, sounding, and satellite-derived atmospheric motion vectors - AMVs) for the Weather Research and Forecasting (WRF) in forecasting heavy rainfall over Central Highlands region, due to the impact of hurricane Damrey. The WRF model combined with the Gridpoint Statistical Interpolation (GSI) system, was started running at $12 \mathrm{Z} 03 / 11 / 2017$, and $84 \mathrm{~h}$ forecasts in advance, with two kinds for running assimilation "cold start" and "warm start", and with the three-dimensional variational data assimilation (3D-Var) method. The results showed that assimilated cases have improved forecasting about spatial distribution and amount of rainfall at a 24-hour lead time, in which, the "warm start" for better forecasting. Notably, the assimilation of AMVs data with the "warm start" run has improved forecasting quality of heavy rainfall, the POD, FAR, and CSI indicators are the best at the 24-hour lead time, for rainfall thresholds greater than $80 \mathrm{~mm}$.
\end{abstract}

Keywords: data assimilation, 3D-Var, WRF-GSI, heavy rainfall, Central Highlands.

\footnotetext{
* Corresponding author.

E-mail address: tranquangduc@hus.edu.vn

https://doi.org/10.25073/2588-1094/vnuees.4478
} 


\title{
Thử nghiệm đồng hóa các loại số liệu quan trắc khác nhau trong dự báo mưa lớn trên khu vực Tây Nguyên do ảnh hưởng của cơn bão Damrey
}

\author{
Lê Lan Phương ${ }^{1}$, Phạm Quang Nam², Trần Quang Đức ${ }^{2, *}$, Phan Văn Tân ${ }^{2}$ \\ ${ }^{1}$ Truờng Đại học Quốc gia Trung uoong, 300 Trung Đại, Trung Lịch, Đào Viên, Đài Loan \\ ${ }^{2}$ Truờng Đại học Khoa học Tự nhiên, Đại học Quốc gia Hà Nội, 334 Nguyễn Trãi, Hà Nội, Việt Nam
}

Nhận ngày 30 tháng 10 năm 2019

Chỉnh sửa ngày 25 tháng 11 năm 2019; Chấp nhận đăng ngày 15 tháng 12 năm 2019

\begin{abstract}
Tóm tắt: Nghiên cứu này xem xét và đánh giá ảnh hưởng của việc đồng hóa các loại số liệu (số liệu quan trắc bề mặt, cao không, và véc-tơ gió khí quyển dịch chuyển của vệ tỉnh - AMVs) cho mô hình Nghiên cứu và Dự báo Thời tiết (WRF) trong dự báo mưa lớn trên khu vực Tây Nguyên, do ảnh hưởng của cơn bão Damrey. Mô hình WRF kết hợp với Hệ thống đồng hóa dữ liệu dạng điểm - GSI được bắt đầu chạy tại thời điểm $12 \mathrm{Z}$ 03/11/2017 và dự báo $84 \mathrm{~h}$ tiếp theo, với số liệu quan trắc được đồng hóa theo hai kiểu "cold start" và "warm start", và với phương pháp đồng hóa 3D-Var. Kết quả cho thấy, các trường hợp đồng hóa đều đã làm cải thiện được dự báo về diện và lượng mưa ở hạn 24h, trong đó, đồng hóa kiểu "warm start" cho dự báo tốt hơn. Đáng chú ý, việc đồng hóa số liệu AMVs với kiểu chạy "warm start" đã làm cải thiện chất lượng dự báo mưa lớn tốt nhất ở hạn $24 \mathrm{~h}$, thể hiện qua các chỉ số thống kê POD, FAR, và CSI đạt tốt nhất với các ngưỡng mưa trên $80 \mathrm{~mm}$.
\end{abstract}

Tiù khoá: đồng hóa số liệu, 3D-Var, WRF-GSI, mưa lớn, Tây Nguyên.

\section{Mở đầu}

Với các hiện tượng thời tiết cực đoan như mưa lớn, bão,..., thì độ chính xác của dự báo luôn được quan tâm và là căn cứ quan trọng cho việc đưa ra những quyết sách ứng phó kịp thời đối với thiên tai. Việc phát triển các mô hình dự báo thời tiết số phi thủy tĩnh với độ phân giải cao, cùng với khả năng tính toán được nâng lên, đã làm cho chất lượng dự báo thời tiết ngày một cải thiện (Yang và cs, 2015) [1]. Tuy nhiên, như đã biết, theo lý thuyết hiệu ứng cánh bướm (butterfly effect) của Lorenz (1963) [2], điều kiện ban đầu về trạng thái khí quyển là yếu tố quyết định đến độ chính xác của dự báo thời tiết do những sai số ban đầu có thể sẽ bị khuếch đại sau một khoảng thời gian tích phân nhất định của mô hình. Do đó, việc tạo ra được trường phân

\footnotetext{
* Tác giả liên hệ.

Địa chi email: tranquangduc@ hus.edu.vn

https://doi.org/10.25073/2588-1094/vnuees.4478
} 
tích ban đầu tốt nhất có thể mang một ý nghĩa rất quan trọng, nó là mục đích ra đời của các phương pháp đồng hóa số liệu, cũng như của các hệ thống đồng hóa số liệu. Trong những năm qua, các sơ đồ đồng hóa cổ điển như nội suy tối ưu (OI Optimal Interpolation), hay hiệu chỉnh liên tiếp (SCM-Successive Correction Method), đã được thay thế bằng các kỹ thuật hiện đại với cách tiếp cận biến phân, như phương pháp đồng hóa biến phân ba và bốn chiều (3D-Var và $4 \mathrm{D}-\mathrm{Var})$ (Courtier và cs, 1998; Rabier và cs, 2000; Mazzarella và cs, 2017) [3-5], và các biến thể tổ hợp của nó. Các phương pháp này thì đều đã được tích hợp vào trong mô hình Nghiên cứu và Dự báo Thời tiết (WRF), và được biết đến với tên gọi WRFDA (Skamarock và cs, 2008; Barker và $\mathrm{cs}, 2012)[6,7]$, nhưng vì WRFDA chỉ được phát triển dành riêng cho mô hình WRF, không mang tính phổ cập, nên sẽ không thể sử dụng được với trường đầu vào từ các mô hình khác. Một hệ thống đồng hóa cho phép thực hiện ý tưởng như vậy, đó là GSI (Gridpoint Statistical Interpolation) - hệ thống đồng hóa dữ liệu dạng điểm, được nghiên cứu và phát triển bởi Trung tâm Thử nghiệm và Phát triển (DTC) của Hoa Kỳ, và hiện đang được sử dụng làm hệ thống đồng hóa dữ liệu toàn cầu (GDAS) nghiệp vụ tại Trung tâm Dự báo Môi trường Quốc gia Hoa Kỳ (NCEP) (Yang và cs, 2015; Hu và cs, 2017; Nam và cs, 2019) $[1,8,9]$. GSI được phát triển giống như là một khung đồng hóa số liệu, mà cho phép hỗ trợ đưa vào nhiều loại trường nền khác nhau của các mô hình v.d. WRF, GFS, NEMS, RTMA, CMAQ, và số liệu quan trắc được đọc dưới định dạng PrepBUFR (NCEP) hoặc BUFR (WMO - World Meteorological Organization) đã được chuẩn hóa.

Bên cạnh việc nghiên cứu và phát triển các phương pháp đồng hóa số liệu, thì việc đánh giá ảnh hưởng của số liệu quan trắc dùng trong đồng hóa cũng là một phần hết sức quan trọng. Ngoài các nguồn số liệu quan trắc truyền thống như bề mặt, cao không,... thì các nguồn số liệu phi truyền thống như số liệu vệ tinh đang dành được sự quan tâm lớn, do lượng thông tin phong phú mang lại, và không ngừng tăng lên cả về chất lượng lẫn số lượng của dữ liệu vệ tinh (Kidd và cs, 2009; Yang và cs, 2015) [10, 11].

Nhằm mục đích xem xét với bộ số liệu quan trắc đồng hóa nào thì chất lượng dự báo mưa lớn của mô hình WRF sẽ cho tốt hơn? Nghiên cứu này sẽ tiến hành chạy thử nghiệm đồng hóa số liệu bằng hệ thống WRF-GSI với phương pháp $3 \mathrm{D}-$ Var, với các bộ số liệu quan trắc khác nhau bao gồm số liệu: bề mặt, cao không, và vector gió khí quyển dịch chuyển-AMVs (Atmospheric Motion Vectors) của vệ tinh mà có được bằng cách xác định sự dịch chuyển của ảnh mây vệ tinh hoặc hơi nước (Forsythe, 2007) [12]. Để dự báo đợt mưa lớn xảy ra trên khu vực Tây Nguyên trong thời gian cơn bão Damrey hoạt động (từ $31 / 10$ đến $05 / 11$ năm 2017). Chi tiết về nguồn số liệu quan trắc, và phương pháp sử dụng được đưa ra ở phần 2 , kết quả và thảo luận ở phần 3 .

\section{Số liệu, phương pháp và thiết kế thí nghiệm}

Trong nghiên cứu này, mô hình WRF phiên bản 3.9.1, phi thủy tĩnh, với hệ các phương trình nguyên thủy ba chiều (Skamarock và ccs, 2008) [5] được chạy với điều kiện ban đầu và điều kiện biên xung quanh là của số liệu dự báo toàn cầu GFS (Global Forecast System) với độ phân giải ngang $0.5 \times 0.5$ độ kinh vĩ, được tải về từ https://www.ncdc.noaa.gov/data-access/modeldata/model-datasets/global-forcast-system-gfs. Mô hình được cấu hình với hai miền tính, tâm miền tính thứ nhất ở 15.874 độ vĩ Bắc và 107.26 độ kinh Đông, trong đó miền d01 có phân giải ngang $12 \mathrm{~km}$ với $212 \times 212$ điểm lưới, miền $\mathrm{d} 02$ là $3 \mathrm{~km}$ với 209×209 điểm lưới (Hình 1), số mực thẳng đứng là 38 mực, và thời gian mô hình tích phân là 30 giây. Các sơ đồ tham số hóa được sử dụng cho mô hình WRF bao gồm: vi vật lý Thompson, bức xạ sóng ngắn Dudhia, bức xạ sóng dài RRTM (Rapid Radiative Transfer Model), bề mặt đất Noah, đối lưu Betts-MillerJanjic, và sơ đồ lớp biên hành tinh YSU (Yonsei University)(http://www2.mmm.ucar.edu/wrf/use rs/docs/user_guide_V3/ARWUsersGuideV3.9.p df, lần truy cập cuối: 03/08/2019). 
Việc đồng hóa số liệu cho mô hình WRF được thực hiện bằng hệ thống GSI phiên bản 3.6, với phương pháp đồng hóa 3D-Var, và với các loại số liệu quan trắc khác nhau, bao gồm: số liệu bề mặt, cao không, và AMVs. Số liệu này được trích xuất với các mã tương ứng cho mỗi loại từ bộ số liệu đã được chuẩn hóa bởi NCEP với định dạng PrepBUFR, lấy về tại https://rda.ucar.edu/ datasets/ds337.0. Chi tiết về các điểm dữ liệu có trong miền tính được minh họa như trên Hình 1 và Hình 2 , và các biến trường như trong bảng 2 . Nghiên cứu chạy mô hình trong thời gian có cơn bão Damrey hoạt động, thời điểm bắt đầu chạy mô hình là tại $12 \mathrm{Z}$ 03/11/2017 dự báo cho $84 \mathrm{~h}$ tiếp theo, với đồng hóa được thực hiện ngay tại thời điểm chạy mô hình hay đồng hóa kiểu "cold start”, kết hợp với các loại số liệu quan trắc khác nhau, và cả không đồng hóa tạo thành bốn trường hợp thử nghiệm (bảng 1).

Bảng 1. Mô tả các trường hợp thí nghiệm

\begin{tabular}{|c|c|c|}
\hline Tên thí nghiệm & Mô tả & Số liệu dùng để đồng hóa \\
\hline NoDA & Không đồng hóa & Không có \\
\hline DA-Obs & \multirow{3}{*}{ Đồng hóa biến phân 3 chiều } & Bề mặt, và cao không \\
\hline DA-AMVs & & Vec-tơ gió khí quyển dịch chuyển của vệ tinh \\
\hline DA-Obs+AMVs & & Cả hai bộ số liệu \\
\hline
\end{tabular}

Bảng 2. Các biến trường của số liệu quan trắc, $\mathrm{U}, \mathrm{V}$ là thành phần gió kinh vĩ hướng, $\mathrm{Q}$ là độ ẩm tuyệt đối, $\mathrm{P}$ là khí áp, và $\mathrm{Z}$ là độ cao địa thế vị

\begin{tabular}{llc}
\hline \multicolumn{1}{c}{ Loại số liệu } & \multicolumn{1}{c}{ Các biến } & Tổng số điểm có trong miền tính d01 \\
\hline Bề mặt & $\mathrm{P}, \mathrm{U}, \mathrm{V}$ & 77 \\
\hline Cao không & $\mathrm{P}, \mathrm{Z}, \mathrm{U}, \mathrm{V}, \mathrm{Q}$ & 27 \\
\hline $\begin{array}{l}\text { Vec-tơ gió khí quyển dịch chuyển của vệ } \\
\text { tinh (GOES AMVs) }\end{array}$ & $\mathrm{P}, \mathrm{U}, \mathrm{V}$ & 2354 \\
\hline
\end{tabular}

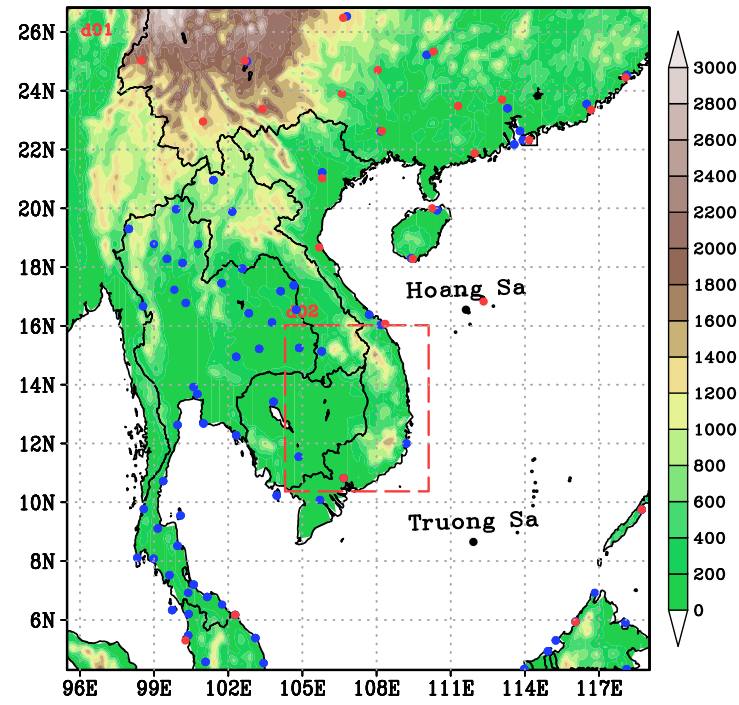

Hình 1. Miền tính mô hình WRF và độ cao địa hình $(\mathrm{m})$, và vị trí số liệu quan trắc bề mặt (chấm xanh dương), cao không (chấm đỏ) dùng trong đồng hóa.

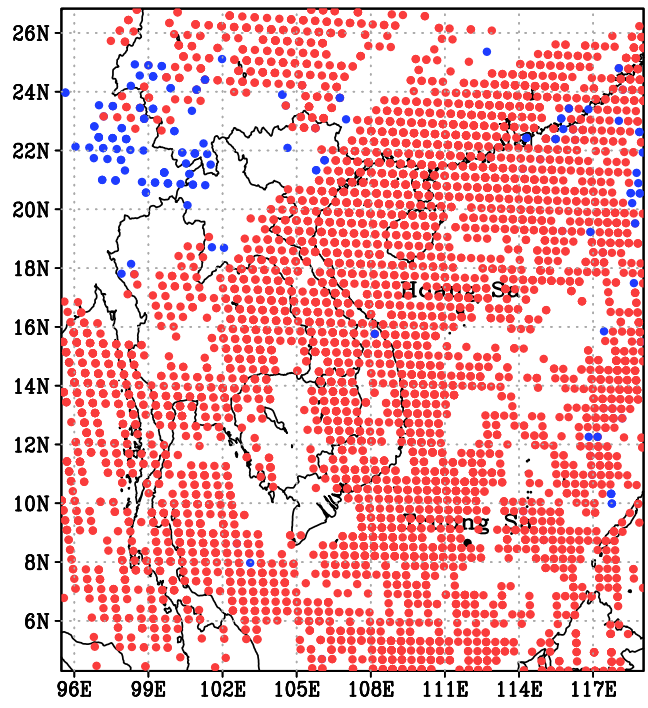

Hình 2. Vị trí số liệu AMVs được đồng hóa, gồm các chấm đỏ $(<=500 \mathrm{mb})$ và chấm xanh dương (>500mb), tại thời điểm 12Z 03/11/2017. 
Thêm nữa, nghiên cứu còn thử nghiệm chạy kiểu "warm start", mô hình cũng được chạy đồng hóa tại thời điểm $12 Z$, nhưng trường nền là trường dự báo của lần chạy trước đó tại $06 \mathrm{Z}$. Kết quả đầu ra của mô hình sẽ được so sánh đánh giá trên lưới với số liệu mưa vệ tinh GSMaP (Global Satellite Mapping of Precipitation), lấy về tại https://sharaku.eorc.jaxa.jp/GSMaP/index.htm, có phân giải $0.1 \times 0.1$ độ kinh vĩ. Để đánh giá khả năng dự báo pha mưa của các trường hợp, các chỉ số thống kê sẽ được tính toán gồm chỉ số POD (xác suất phát hiện), FAR (tỷ số dự báo sai), và CSI (điểm số thành công) (Wilks, 2011) [13]. Các chỉ số này đều có giá trị nằm trong khoảng $[0,1]$, miêu tả vắn tắt về các chỉ số như sau:

- POD là phần trăm của số lần dự báo hiện tượng có xảy ra trên tổng số lần quan trắc được, lý tưởng là bằng 1 .

- FAR cho biết tỷ lệ dự báo khống của mô hình (mô hình dự báo có nhưng thực tế hiện tượng không xảy ra), lý tưởng là bằng 0 .

- CSI giống như POD nhưng đưa thêm vào cả số lần dự báo sai, do đó cân bằng hơn $\mathrm{POD}$ hoặc FAR, lý tưởng là bằng 1

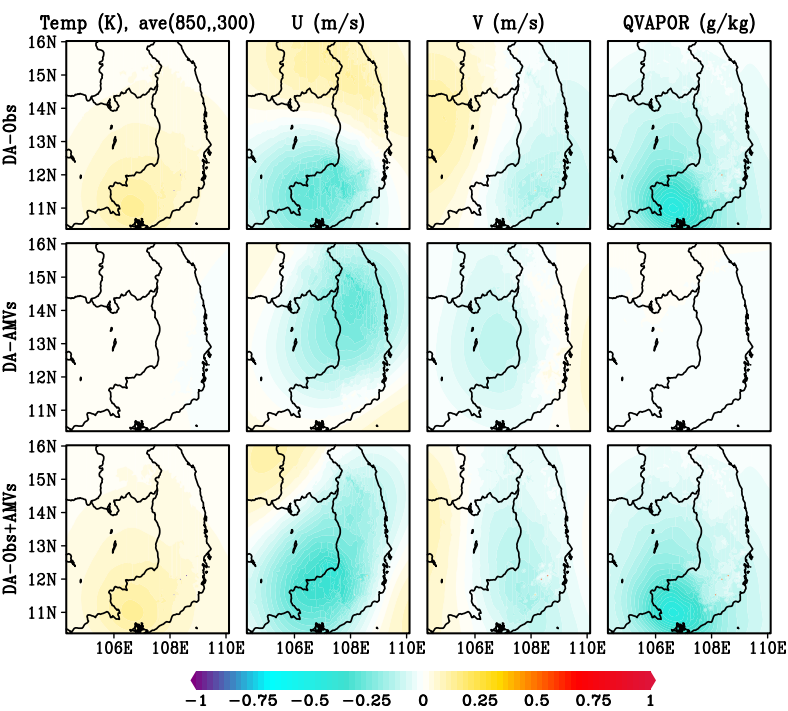

Hình 3. Hiệu các trường phân tích của các trường hợp đồng hóa và không đồng hóa tại thời điểm $12 \mathrm{Z}$ 03/11/2017, trên miền tính $\mathrm{d} 02$.

\section{Kết quả và thảo luận}

Trên hình 3 là hiệu các trường phân tích tính trung bình trên các mực $850,700,600,500$, và $300 \mathrm{mb}$ của các trường hợp đồng hóa và không đồng hóa. Có thể thấy rằng trường hợp DA-Obs cho nhiệt độ thiên cao hơn so với không đồng hóa, và ảnh hưởng chủ yếu trên vùng phía nam của miền tính $\mathrm{d} 02$, cũng dễ hiểu bởi có một trạm cao không tại đó (Hình 3, trên cùng). Gió vĩ hướng thì cho thiên thấp ở phía nam, và thiên cao ở phía bắc, trong khi gió kinh hướng cho thiên cao ở phía tây và thiên thấp ở phía đông. Với tỷ lệ xáo trộn hơn nước thì cũng tương tự như nhiệt độ, nhưng xu thế ngược lại, cho thiên thấp. Vì trường hợp DA-AMVs đưa vào đồng hóa trường gió nên dễ dàng nhận ra sự thay đổi chủ yếu xảy ra với các trường gió, và cũng cho thiên cao hơn, có thể nhận ra rằng sự thay đổi này là đồng đều hơn so với DA-Obs, lý do bởi AMVs có nhiều dữ liệu hơn. Còn với trường hợp DAObs+AMVs, như là sự hòa hợp của hai trường hợp đồng hóa DA-Obs và DA-AMVs, nên sự thay đổi của thông tin các trường sẽ nhiều hơn, đặc biệt là với trường gió (Hình 3 , dưới cùng).

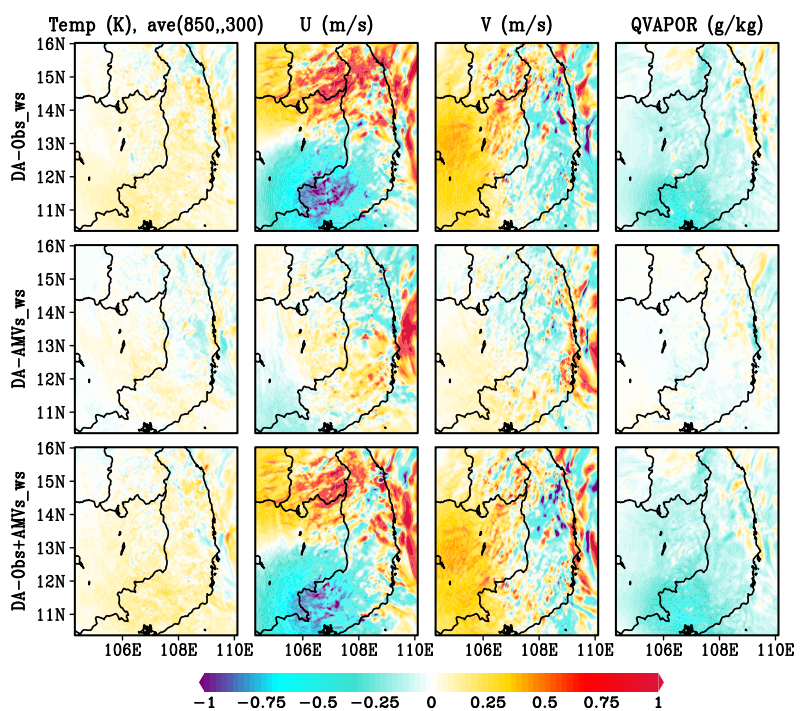

Hình 4. Tương tự như hình 3 nhưng cho kiểu chạy "warm start". 
Hình 4 cũng tương tự như vậy, là hiệu của các trường hợp đồng hóa kiểu "warm start" và không đồng hóa. Tuy nhiên, sự thay đổi của các trường nhiều hơn so với trên Hình 3 , và có vẻ như thông tin có sự phân tán (nhiễu) tăng lên, điều này cũng dễ hiểu bởi đây là thời điểm sau thời điểm ban đầu 6 giờ, sai số của các trường sẽ khuếch đại tăng dần theo mỗi bước thời gian mô hình tích phân.

Hình 5 là kết quả dự báo lượng mưa tích lũy $24 \mathrm{~h}$ của hệ thống mô hình WRF-GSI trên miền tính d02 với ba hạn dự báo $24 \mathrm{~h}, 48 \mathrm{~h}$, và $72 \mathrm{~h}$, với thời điểm bắt đầu chạy mô hình là tại $12 \mathrm{Z}$ 03/11/2017 trong thời gian hoạt động của cơn bão Damrey, và được đồng hóa với ba nguồn số liệu quan trắc khác nhau. So sánh với số liệu mưa vệ tinh GSMaP đã được trích xuất tương ứng, thì có thể nhận thấy rằng các trường hợp đều cho dự báo khu vực xuất hiện mưa giống nhau, khác biệt chỉ thể hiện qua lượng mưa. Trong đó, mưa dự báo của các trường hợp đồng hóa có $\mathrm{xu}$ hướng tiệm cận gần hơn đến với GSMaP (hình 6), và hai trường hợp $\mathrm{DA}-\mathrm{Obs}$ và $\mathrm{DA}-\mathrm{Obs}+\mathrm{AMVs}$ cho dự báo về lượng mưa khá tương đồng với nhau ở tất cả các hạn dự báo, còn với trường hợp DA-
AMVs thì có xu hướng dự báo khu vực có lượng mưa $>100 \mathrm{~mm}$ nhiều hơn các trường hợp khác.

Ở hạn $24 \mathrm{~h}$, nhìn chung các trường hợp đều đã dự báo được khu vực xuất hiện mưa tương đối sát so với số liệu GSMaP trên cả đất liền và trên biển, đặc biệt, đã nắm bắt tốt được khu vực có lượng mưa $>20 \mathrm{~mm}$. Đối với khu vực có lượng mưa $>100 \mathrm{~mm}$, các trường hợp đều có xu hướng cho dự báo diện mưa lớn hơn so với thực tế ở phía bắc của Duyên hải Nam Trung Bộ, trong khi đó, tại phía nam thì diện mưa nhỏ hơn. Ở hạn 48h, các trường hợp cho dự báo về diện mưa lớn hơn mưa GSMaP, cụ thể, mưa chủ yếu tập trung ở nửa phía bắc của miền tính, trong khi dự báo cho mưa xuất hiện trên hầu hết toàn miền tính. Theo số liệu GSMaP, khu vực có lượng mưa $>50 \mathrm{~mm}$ tập trung chủ yếu ở phía bắc của Tây Nguyên và Duyên hải Nam Trung Bộ, và các trường hợp $\mathrm{DA}-\mathrm{Obs}$ và $\mathrm{DA}-\mathrm{Obs}+\mathrm{AMV}$ nắm bắt khá tốt vùng mưa này. Tương tự như hạn $48 \mathrm{~h}$, ở hạn 72h, dự báo của các trường hợp cũng có diện mưa mở rộng hơn so với thực tế, nhất là trường hợp DA-AMVs. Dự báo về lượng mưa cũng chưa tốt, các trường hợp đều có xu hướng có lượng mưa lớn hơn.

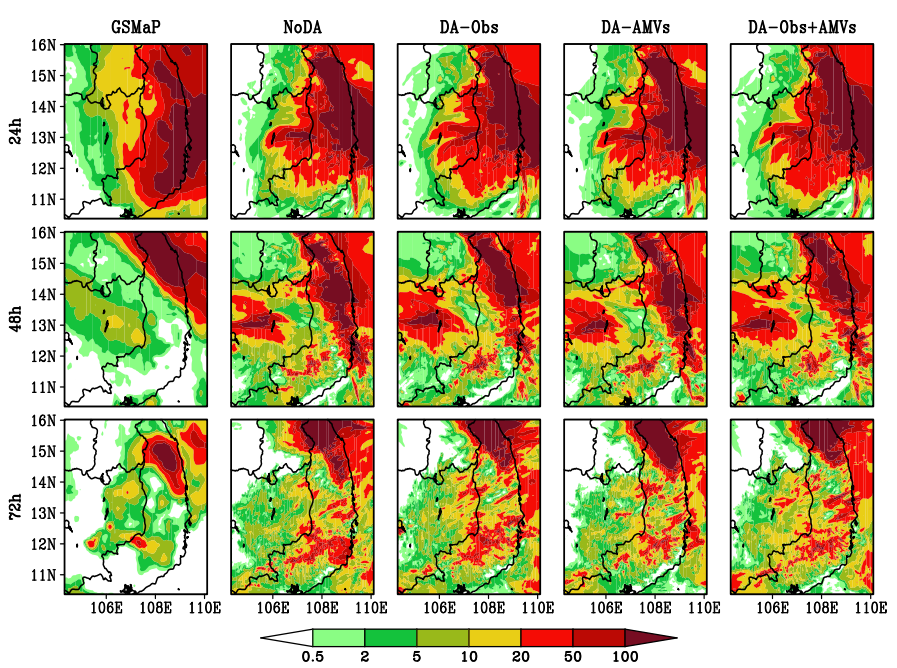

Hình 5. Lượng mưa $24 \mathrm{~h}(\mathrm{~mm})$ của số liệu GSMaP, và dự báo mô hình trên miền tính $\mathrm{d} 02$ của các trường hợp NoDA, DA-Obs, DA-AMVs và DA-Obs+AMVs, ở các hạn dự báo $24 \mathrm{~h}, 48 \mathrm{~h}$ và $72 \mathrm{~h}$, với thời điểm bắt đầu chạy tại $12 \mathrm{Z}$ 03/11/2017.

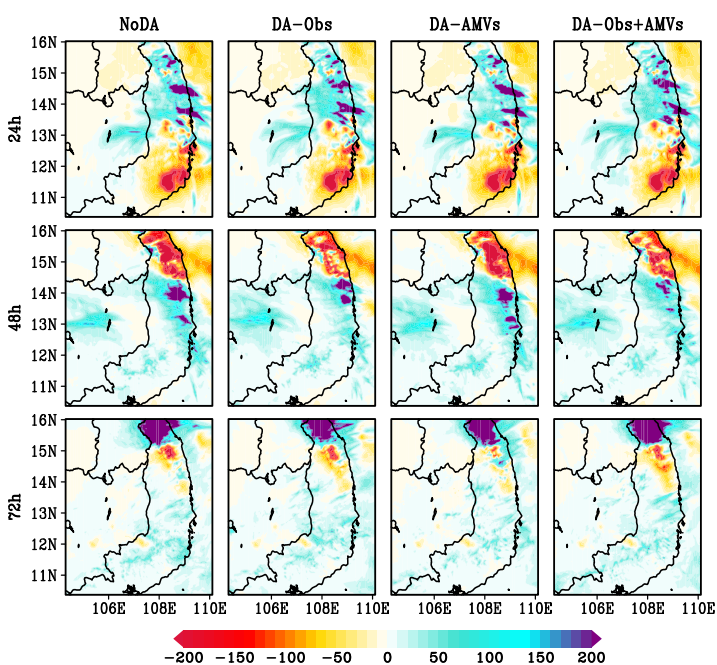

Hình 6. Hiệu lượng mưa 24h (mm) của dự báo mô hình trên miền tính d02 của các trường hợp đồng hóa và số liệu GSMaP, ở các hạn dự báo 24h, 48h và $72 \mathrm{~h}$, với thời điểm bắt đầu chạy tại $12 \mathrm{Z}$ 03/11/2017. 


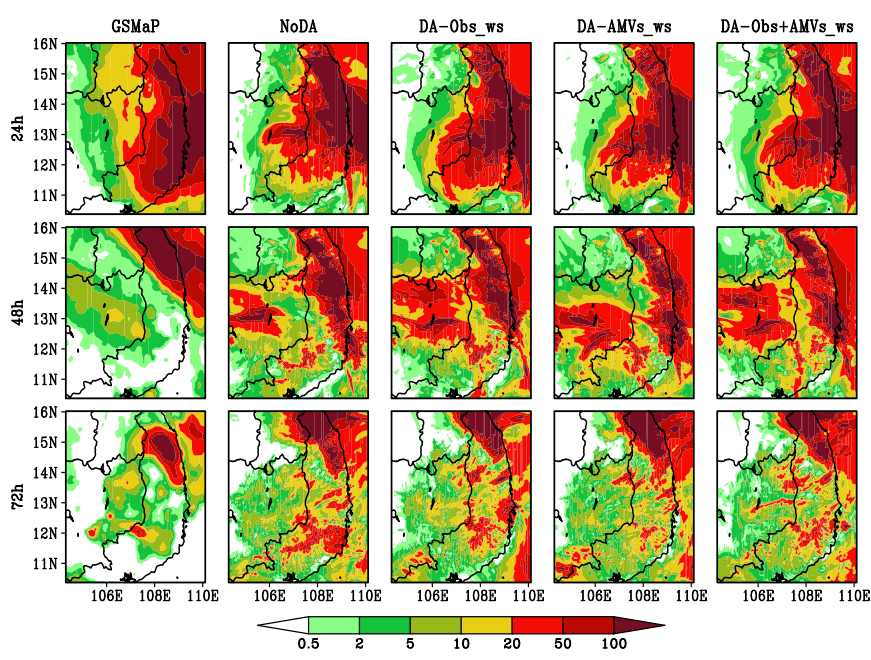

Hình 7. Tương tự như hình 5 nhưng cho kiểu chạy "warm start".

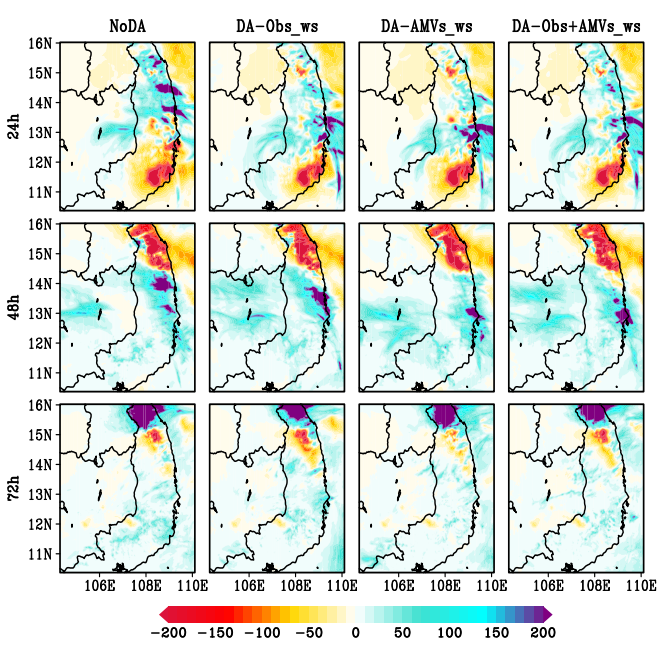

Hình 8. Tương tự như hình 6 nhưng cho kiểu chạy "warm start".
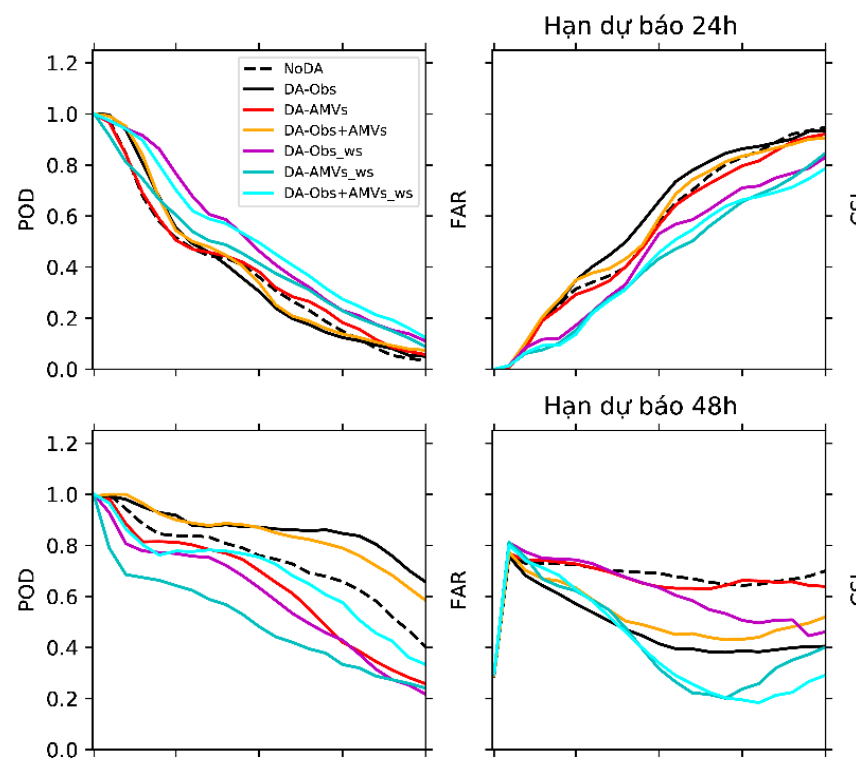

Hạn dự báo $72 \mathrm{~h}$
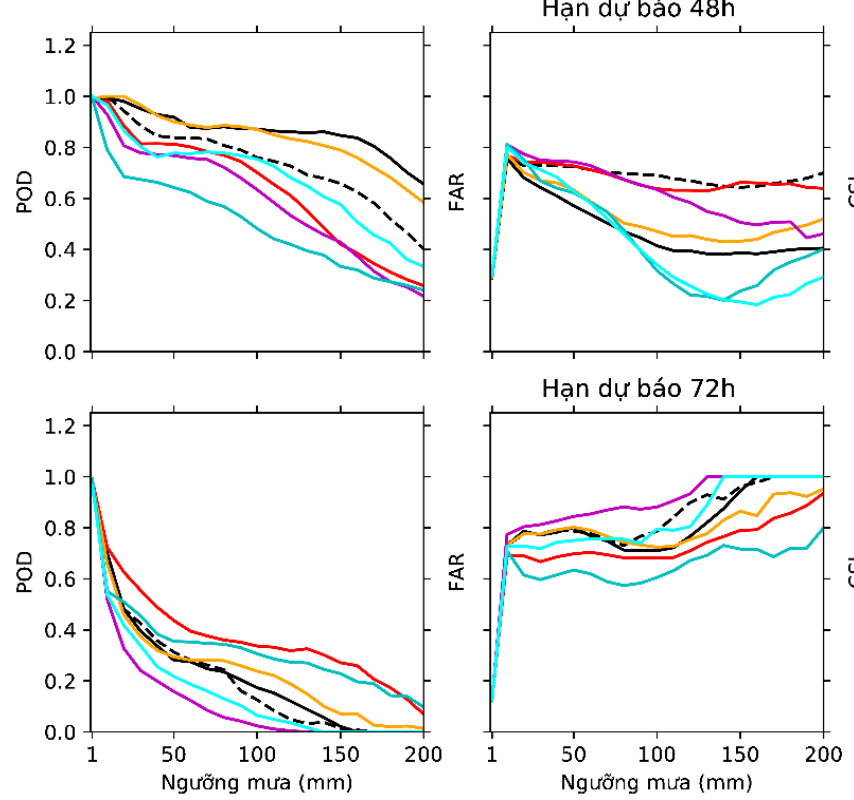
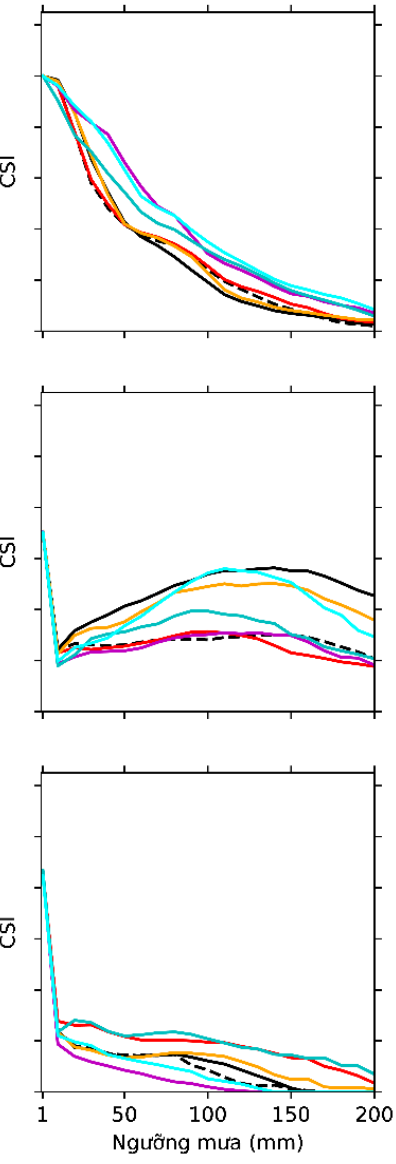

Hình 9. Các chỉ số thống kê POD, FAR, CSI. 
Như đã thông tin trong phần thiết kế thí nghiệm, ngoài việc đồng hóa số liệu cho mô hình ngay tại thời điểm chạy, thì nghiên cứu còn chạy thử nghiệm kiểu "warm start". Kết quả dự báo lượng mưa của mô hình trên miền tính $\mathrm{d} 02$ với ba hạn dự báo được thể hiện trên hình 7 , thêm đuôi ký hiệu “_ws” để phân biệt. So sánh giữa các trường hợp dự báo cho thấy, sự tương đồng cũng thể hiện ở khu vực xuất hiện mưa. Tuy nhiên, khác với trường hợp "cold start" (hình 5), ở đây hai trường hợp DA-Obs_ws và DAObs+AMVs_ws cho kêt quả dự báo lượng mưa khá tương đồng ở hạn $48 \mathrm{~h}$ và $72 \mathrm{~h}$. Nhìn chung, các trường hợp có xu hướng dự báo khu vực xuất hiện mưa nhỏ hơn thực tế ở hạn dự báo 24h (hình 7). Về lượng mưa, thì dự báo cũng đã nắm bắt khá tốt khu vực có lượng mưa $>20 \mathrm{~mm}$, còn với khu vực có lượng mưa $>100 \mathrm{~mm}$ thì lệch về phía bắc so với thực tế, nhưng độ lệch nhỏ hơn so với các trường hợp đồng hóa kiểu "cold start". Ở hạn $48 \mathrm{~h}$, giống như hình 5 , dự báo cho mưa xuất hiện trên gần như toàn miền tính, đối với khu vực có lượng mưa $>50 \mathrm{~mm}$, các trường hợp đều nắm bắt chưa tốt, ngoại trừ trường hợp DA-Obs_ws đã cho dự báo tốt hơn. Còn với hạn $72 \mathrm{~h}$, thì dự báo cũng có xu hướng lớn hơn thực tế cả về diện và lượng mưa (hình 8).

Phần tiếp theo sẽ sử dụng các chỉ số thống kê POD, FAR, và CSI, để đánh giá khả năng dự báo các pha mưa của mô hình chạy với các trường hợp số liệu đồng hóa khác nhau. Kết quả tính toán các chỉ số được biểu diễn bằng biểu đồ trên hình 9 , với trục tung là giá trị của chỉ số và trục hoành là các ngưỡng mưa chia theo mỗi khoảng $10 \mathrm{~mm}$ từ 0 đến $200 \mathrm{~mm}$. Ở đây, toàn bộ số điểm lưới của mô hình và số liệu GSMaP nằm trong khu vực Tây Nguyên đã được trích xuất để dùng trong tính toán nhằm đảm bảo dung lượng mẫu, số điểm khoảng 7201.

Với ngưỡng mưa nhỏ hơn 20mm, ở hạn 24h, các trường hợp "cold start" với đồng hóa DAObs và DA-Obs+AMVs đã cho các chỉ số thống kê $P O D$ và $C S I$ tốt hơn các trường hợp khác (gồm cả không đồng hóa, và đồng hóa chạy kiểu "warm start"). Với ngưỡng mưa nằm trong khoảng 20-80mm, trường hợp DA-Obs_ws có hai chỉ số POD và CSI đạt cao nhất (POD khoảng
0.6-0.95; CSI khoảng 0.5-0.9). Còn với các ngưỡng mưa lớn hơn $80 \mathrm{~mm}$, trường hợp $\mathrm{DA}$ Obs+AMVs_ws cho cả ba chỉ số tốt nhất. Chỉ số FAR của trường hợp DA-AMVs ws đạt thấp nhất (khoảng 0.25-0.6) với các ngưỡng mưa nằm trong khoảng $80-150 \mathrm{~mm}$. Như vậy, có thể đưa ra kết luận rằng trường hợp đồng hóa "warm start" với số liệu AMVs đã cho cải thiện về dự báo mưa lớn tốt hơn các trường hợp khác.

Các chỉ số của các trường hợp đồng hóa ở hai hạn dự báo $48 \mathrm{~h}$ và $72 \mathrm{~h}$ có sự biến động nhiều hơn, nguyên nhân là do lượng mưa quan trắc đã giảm xuống (Hình 5), và mô hình cho dự báo khống. Tuy nhiên, vẫn có thể nhận ra rằng các trường hợp đồng hóa "warm start" cho chỉ số FAR tốt hơn cả.

\section{Kết luận}

Trong nghiên cứu này, các loại số liệu quan trắc khác nhau đã được đồng hóa cho mô hình WRF theo phương pháp 3D-Var bởi hệ thống đồng hóa GSI. Để khảo sát và đánh giá ảnh hưởng của các loại số liệu đồng hóa đối với dự báo mưa lớn của mô hình $\mathrm{WRF}$, trên khu vực Tây Nguyên, do ảnh hưởng của cơn bão Damrey. Hệ thống mô hình WRF-GSI được bắt đầu chạy tại thời điểm $12 \mathrm{Z}$ 03/11/2017 và dự báo $84 \mathrm{~h}$ tiếp theo, với số liệu quan trắc được đồng hóa theo hai kiểu "cold start" và "warm start". Qua việc Phân tích và đánh giá, có thể rút ra được các nhận xét như sau:

Các trường hợp đồng hóa đều cho dự báo mưa tương đối tốt về diện và lượng mưa ở hạn $24 \mathrm{~h}$ so với số liệu mưa GSMaP, trong đó các trường hợp có đồng hóa kiểu "warm start" cho dự báo tốt hơn so với "cold start".

Việc đồng hóa số liệu AMVs với kiểu chạy "warm start" đã làm cải thiện chất lượng về dự báo mưa lớn, các chỉ số thống kê đạt tốt nhất ở hạn dự báo $24 \mathrm{~h}$, với các ngưỡng mưa lớn hơn $80 \mathrm{~mm}$. Với các hạn dự báo $48 \mathrm{~h}$ và $72 \mathrm{~h}$, các chỉ số có sự biến động nhiều hơn do mô hình đã cho dự báo khống, tuy nhiên so với "cold start" các trường hợp đồng hóa "warm start" vẫn cho chỉ số FAR tốt hơn. 


\section{Lời cảm ơn}

Nghiên cứu này được thực hiện và hoàn thành với sự hỗ trợ của Đề tài nghiên cứu khoa học KC.09.15/16-20, thuộc chương trình KC.09, Bộ Khoa học và Công nghệ. Tập thể tác giả xin chân thành cảm ơn.

\section{Tài liệu tham khảo}

[1] Y. Yang, Y. Wang, and K. Zhu, Assimilation of Chinese Doppler Radar and Lightning Data Using WRF-GSI: A Case Study of Mesoscale Convective System, Advances in Meteorology (2015). https://doi.org/10.1155/2015/763919.

[2] E. N. Lorenz, Deterministic nonperiodic flow, J. Atmos. Sci. 20 (1963) 130-141. https://doi.org/ 10. 1175/1520-0469(1963) 020<0130:DNF>2.0.CO;2.

[3] P. Courtier, E. Andersson, W. Heckley, D. Vasiljevic, M. Hamrud, A. Hollingsworth, F. Rabier, M. Fisher, and J. Pailleux, The ECMWF implementation of three- dimensional variational assimilation (3D- Var). I: Formulation, Quarterly Journal of the Royal Meteorological Society 124 (1998) 1783-1807.

[4] F. Rabier, H. Järvinen, E. Klinker, J.F. Mahfouf, and A. Simmons, The ECMWF operational implementation of four- dimensional variational assimilation. I: Experimental results with simplified physics, Q.J.R. Meteorol. Soc. 126 (2000) 1143-1170.

[5] V. Mazzarella, I. Maiello, V. Capozzi, G. Budillon, and R. Ferretti, Comparison between 3D-Var and 4D-Var data assimilation methods for the simulation of a heavy rainfall case in central Italy, Adv. Sci. Res. 14 (2017) 271-278. https://doi.org/ 10.5194/asr-14-271-2017.
[6] W.C. Skamarock, J.B. Klemp, J. Dudhia, D.O. Gill, D.M. Barker, M.G. Duda, X.Y. Huang, W. Wang, and J.G. Powers, A description of the Advanced Research WRF Version 3, NCAR Technical Note NCAR/TN-475CSTR (2008).

[7] D. Barker, X.Y. Huang, Z. Liu, T. Auligné, X. Zhang, S. Rugg, R. Ajjaji, A. Bourgeois, J. Bray, Y. Chen, and M. Demirtas, The weather research and forecasting model's community variational/ ensemble data assimilation system: WRFDA, Bull. Amer. Meteor. Soc. 93 (2012) 831-843.

[8] M. Hu, G. Ge, H. Shao, D. Stark, K. Newman, C. Zhou, J. Beck, X. Zhang, Grid-point Statistical Interpolation (GSI) User's Guide v3.6, Developmental Testbed Center (2017).

[9] P.Q. Nam, M.V. Khiem, N.Q. Trung, V.V. Thang, An experiment with GSI system for data assimilation to improve quantitative rainfall forecast over southern Vietnam region (in Vietnamese), Vietnam Journal of Hydrometeorology 698 (2019) 1-10.

[10] C. Kidd, V. Levizzani, \& P. Bauer, A review of satellite meteorology and climatology at the start of the twenty-first century, Progress in Physical Geography 33 (2009) 474-489.

[11] J. Yang, K. Duan, J. Wu, X. Qin, P. Shi, H. Liu, X. Xie, X. Zhang, and J. Sun, Effect of data assimilation using WRF-3DVAR for heavy rain prediction on the northeastern edge of the Tibetan Plateau, Advances in Meteorology (2015). https:// doi.org/10.1155/2015/294589.

[12] M. Forsythe, Atmospheric motion vectors: past, present and future, In ECMWF Annual Seminar (2007).

[13] D.S. Wilks, Statistical methods in the atmospheric sciences, Academic press, 2011. 